Mecánica Computacional Vol. XXIII, pp. 2123-2140

G.Buscaglia, E.Dari, O.Zamonsky (Eds.)

Bariloche, Argentina, November 2004

\title{
COMBINED FREE AND FORCED CONVECTION IN AN INCLINED CHANNEL WITH DISCRETE HEAT SOURCES
}

\author{
Paulo M. Guimarães*, Genésio J. Menon ${ }^{\dagger}$ \\ * Departamento de Engenharia Mecânica,Universidade Federal de Itajubá - UNIFEI \\ Av. BPS, 1303, Pinheirinho, 37500-176 - Itajubá - MG - Brasil. TE: 0055 35 3629-1163 \\ e-mail: paulomgui@uol.com.br, web page: http://www.unifei.edu.br \\ $†$ Departamento de Engenharia Mecânica,Universidade Federal de Itajubá - UNIFEI \\ Av. BPS, 1303, Pinheirinho, 37500-176 - Itajubá - MG - Brasil. TE: 0055 35 3629-1163 \\ e-mail: genesio@iem.efei.br, web page: http://www.unifei.edu.br
}

Key Words: Finite Element, Heat Source, Petrov-Galerkin, Mixed Convection.

Abstract. It is studied in this work the mixed convection in an inclined rectangular channel. Three constant heat sources $q$ ' with finite lengths are flush mounted on the bottom surface of a channel, while the remaining part of this surface is kept isolated. The upper wall is cooled at a constant cold temperature $T_{c}$. At the inlet, the flow has constant velocity $U_{o}$ and temperature $T_{o}$ profiles. The Reynolds number, the Grashof number, and the channel inclination angle are ranged as follows: $1 \leq R e \leq 1000,10^{3} \leq \mathrm{Gr} \leq 10^{5}$, e $0^{\circ} \leq \gamma \leq 90^{\circ}$, respectively. The system of the governing equations is solved using the finite element method with the Penalty formulation on the pressure terms and the Petrov-Galerkin perturbations on the convective terms. Three comparisons are carried out to validate the computational code. It is observed that the inclination angle has a stronger influence on the flow and heat transfer for low Reynolds numbers, especially when it is between $0^{\circ}$ and $45^{\circ}$. The cases which present the lowest temperature distributions on the modules are those where the inclination angles are $45^{\circ}$ and $90^{\circ}$ with little difference between them. The case where $\mathrm{Gr}=10^{5}$ and Re $=1000$ is an exception where $\gamma=0^{\circ}$ is the best channel inclination. 


\section{INTRODUCTION}

Previous works study the natural, mixed, and forced convection in inclined channels due to their practical applications such as electronic systems, high performance heat exchangers, chemical process equipments, combustion chambers, environmental control systems and so on.

Guimarães and Menon ${ }^{1}$ study the mixed convection in an inclined rectangular channel with a flush-mounted heat source placed on the bottom surface. The Petrov-Galerkin scheme is used. It is shown that the inclination angle effect on the velocity and temperature distributions plays an important role on heat transfer for low Reynolds numbers and high Grashof numbers. For high Reynolds numbers, the channel orientation is negligible. It is concluded in this work that the inclination angle between $60^{\circ}$ and $75^{\circ}$ provides more desirable work conditions when cooling is aimed. Some cases present reversal flow for low Reynolds and high Grashof numbers. The reversal flow does not noticeably influence the heat transfer on the modules. The results encourage the use of inclined circuits within cabinets. However, other geometrical parameters must be taken into consideration.

Bae and Hyun ${ }^{2}$ carry out a study on air cooling in a unsteady laminar natural convection in a vertical rectangular channel with three flush-mounted heat sources on one vertical wall. The results show the effects of the thermal conditions of the lowest source on the downstream sources. The evolution of the temperature and flow fields gives physical interpretations. The study emphasizes that the transient temperatures may exceed average values in time. This is important for designing electronic equipment projects.

Madhavan and Sastri ${ }^{3}$ develop a parametric study of natural convection in a set of boards inside an enclosure. Each board has heat sources. This layout has direct application on electronic equipment cooling. It is noted that the Rayleigh and the Prandtl numbers as well as the boundary conditions strongly affect the fluid flow and the heat transfer features. As a conclusion, they say that the dimensionless temperature is maximum for $\operatorname{Pr}=150$. Numerical correlations for maximum temperature on the protruding regions and for Nusselt number are presented for a wide range of $\mathrm{Pr}, \mathrm{Ra}$, and boundary conditions.

Choi and Ortega ${ }^{4}$ investigate numerically the effect of the laminar forced flow on the convection cells generated by buoyancy forces in channels with parallel plane plates and one discrete heat source. In general, the results show that the Nusselt number on the module strongly depends on the channel inclination angle. As the Grashof number is increased for a fixed value of the Reynolds number, there is an air reversion at the channel outlet when it is in the aiding flow position.

In the present work, a heat transfer study in an inclined rectangular channel with heat sources is conducted. The vertical and horizontal positions are also considered. Emphasis is given to the temperature distributions on the modules showing their maximum temperature points due to their importance when thermal control in electronic equipments is aimed.

\section{PROBLEM DESCRIPTION}

In this work, mixed convection is studied in an inclined rectangular channel with height $\mathrm{H}$ and length L, as shown in Fig. 1. Three constant heat sources q'1, q'2, and q'3 of length B are 
placed on the bottom wall of the channel in $\mathrm{x}_{1}, \mathrm{x}_{2}$, and $\mathrm{x}_{3}$, respectively. The remaining lower wall is isolated. The upper wall in contact with the fluid is constantly cooled at temperature $T_{c}$. At the inlet, constant velocity and temperature profiles, $U_{0}$ and $T_{0}$, are applied as boundary conditions. As for the ones at the outlet, they are considered convective and time dependent. In fact, in the method applied here, the open boundary conditions OBC are calculated and, hence nothing is directly applied at the exit. Throughout this study, the geometry has $\mathrm{x}_{1}=6.75 \mathrm{~cm}, \mathrm{x}_{2}=14.50 \mathrm{~cm}, \mathrm{x}_{3}=22.25 \mathrm{~cm}, \mathrm{~B}=\mathrm{H}=1 \mathrm{~cm}$, and $\mathrm{L}=30 \mathrm{~cm}$. Temperatures $\mathrm{T}_{\mathrm{o}}$ and $\mathrm{T}_{\mathrm{c}}$ are equal to zero.

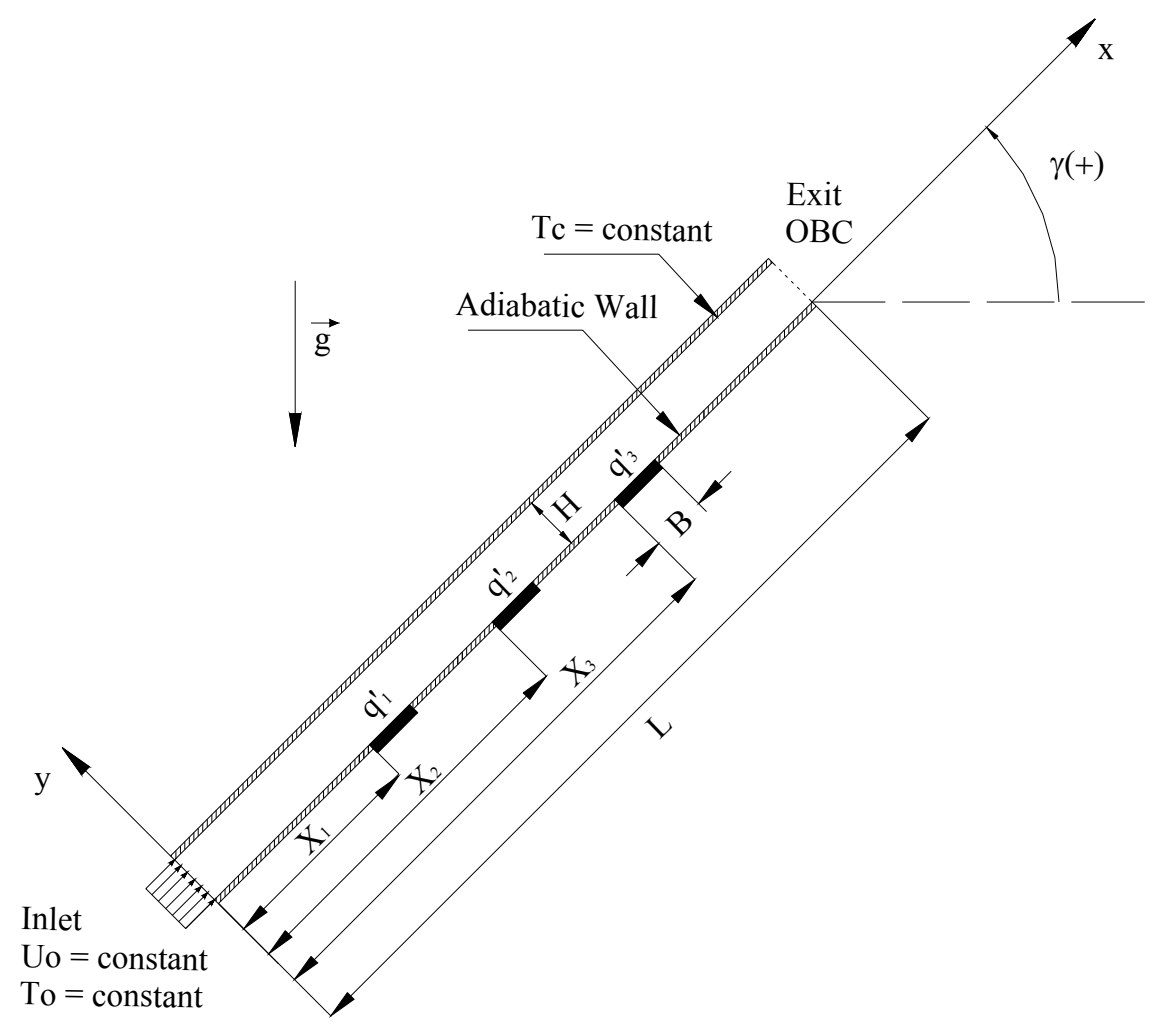

Figure 1: Channel geometry and boundary conditions.

\section{PROBLEM FORMULATION}

The problem governing equation set is given by the continuity, Navier-Stokes, and energy equations. Variables $u$ and $v$ are, respectively, the velocity components in $x$ and $y$ directions, $T$ is the fluid temperature, $t$ ' is the time, $q$ ' is the heat flux, $D_{T}$ is the fluid thermal diffusivity, $\beta_{T}$ is the thermal expansion coefficient, $v$ is the kinematics viscosity, $g$ is the gravity acceleration, $\rho_{0}$ is the fluid density, and $T_{o}$ is the reference temperature taken as $T_{o}=T_{c}$ and $\Delta T=T_{h}-T_{c}$.

Considering the Boussinesq approximation and the following dimensionless parameters: 


$$
\begin{gathered}
X=\frac{x}{B} ; \quad Y=\frac{y}{B} ; \quad U=\frac{u}{U_{o}} ; \quad V=\frac{v}{U_{o}} ; P=\frac{p}{\rho_{0} U_{o}^{2}} ; t=\frac{t^{\prime}}{\left(B / U_{o}\right)^{\prime}} ; \theta=\left(T-T_{o}\right) /\left(q^{\prime} B / D_{T}\right) ; \\
F r=\frac{\operatorname{Re}{ }^{2}}{G r}=\frac{U_{o}^{2}}{\beta_{T} g \Delta T B} ; \quad \operatorname{Pr}=\frac{v}{D_{T}} ; \quad G r=\frac{\beta_{T} g \Delta T B^{3}}{v^{2}} ; \quad \operatorname{Re}=\frac{U_{o} \rho_{0} B}{\mu} ;
\end{gathered}
$$

where $F r, P r, G r, R e, U_{o}$, and $\mu$ are, respectively, the Froude number, the Prandtl number, the Grashof number, the Reynolds number, the average velocity, and the dynamic viscosity, the dimensionless governing equations can be cast into the following form:

$$
\begin{aligned}
& \frac{\partial U}{\partial X}+\frac{\partial V}{\partial Y}=0 \\
& \frac{\partial U}{\partial t}+U \frac{\partial U}{\partial X}+V \frac{\partial U}{\partial Y}=-\frac{\partial P}{\partial X}+\frac{1}{R e}\left(\frac{\partial^{2} U}{\partial X^{2}}+\frac{\partial^{2} U}{\partial Y^{2}}\right)+\sin (\gamma) \frac{\theta}{F r} ; \\
& \frac{\partial V}{\partial t}+U \frac{\partial V}{\partial X}+V \frac{\partial V}{\partial Y}=-\frac{\partial P}{\partial Y}+\frac{1}{R e}\left(\frac{\partial^{2} V}{\partial X^{2}}+\frac{\partial^{2} V}{\partial Y^{2}}\right)+\cos (\gamma) \frac{\theta}{F r} ; \\
& \frac{\partial \theta}{\partial t}+U \frac{\partial \theta}{\partial X}+V \frac{\partial \theta}{\partial Y}=\frac{1}{\operatorname{RePr}}\left(\frac{\partial^{2} \theta}{\partial X^{2}}+\frac{\partial^{2} \theta}{\partial Y^{2}}\right)
\end{aligned}
$$

The dimensionless boundary conditions are:

$$
U=V=0 \quad \text { (all walls); } \theta=0 \text { (inlet and upper walls); } U=1 \text { (inlet) and } \frac{\partial \theta}{\partial Y}=-1 \text { (sources). }
$$

Applying the Petrov-Galerkin formulation and the Penalty technique to Eqs. (2) to (5), the weak forms of the conservation equations are:

$$
\begin{gathered}
\int_{\Omega} N_{i}\left[\frac{\partial U}{\partial t}+\frac{1}{\operatorname{Re}}\left(\frac{\partial N_{i}}{\partial X} \frac{\partial U}{\partial X}+\frac{\partial N_{i}}{\partial Y} \frac{\partial U}{\partial Y}\right)\right] d \Omega+\int_{\Omega}^{R} \lambda \frac{\partial N_{i}}{\partial X}\left(\frac{\partial U}{\partial X}+\frac{\partial V}{\partial Y}\right) d \Omega= \\
\int_{\Omega}\left[\left(N_{i}+P_{i 1}\right)\left(U \frac{\partial U}{\partial X}+V \frac{\partial U}{\partial Y}\right)+N_{i} \sin (\gamma) \frac{\theta}{F r}\right] d \Omega-\int_{\Gamma_{0}} N_{i} p n_{x} d \Gamma \\
\int_{\Omega} N_{i}\left[\frac{\partial V}{\partial t}+\frac{1}{\operatorname{Re}}\left(\frac{\partial N_{i}}{\partial X} \frac{\partial V}{\partial X}+\frac{\partial N_{i}}{\partial Y} \frac{\partial V}{\partial Y}\right)\right] d \Omega+\int_{\Omega}^{R} \lambda \frac{\partial N_{i}}{\partial Y}\left(\frac{\partial U}{\partial X}+\frac{\partial V}{\partial Y}\right) d \Omega= \\
\int_{\Omega}\left[\left(N_{i}+P_{i l}\right)\left(U \frac{\partial V}{\partial X}+V \frac{\partial V}{\partial Y}\right)+N_{i} \cos (\gamma) \frac{\theta}{F r}\right] d \Omega-\int_{\Gamma_{0}} N_{i} p n_{y} d \Gamma \\
\int_{\Omega}\left[N_{i} \frac{\partial \theta}{\partial t}+\frac{1}{\operatorname{RePr} \operatorname{Pr}}\left(\frac{\partial N_{i}}{\partial X} \frac{\partial \theta}{\partial X}+\frac{\partial N_{i}}{\partial Y} \frac{\partial \theta}{\partial Y}\right)\right] d \Omega=\int_{\Omega}\left(N_{i}+P_{i 2}\right)\left(U \frac{\partial \theta}{\partial X}+V \frac{\partial \theta}{\partial Y}\right) d \Omega+\int_{\Gamma_{l}} N_{i} q d \Gamma
\end{gathered}
$$

where the dependent variables are approximated through the finite element method (FEM) by: 


$$
\Phi(X, Y, t)=\sum_{j} N_{j}(X, Y) \Phi_{j}(t) ; p(X, Y, t)=\sum_{k} M_{k}(X, Y) p_{k}(t)
$$

$N_{i}$ and $N_{j}$ are linear shape functions for the quantity $\Phi$, that is, for $U, V$, and $\theta . M_{k}$ are the pressure piecewise element shape functions. The Petrov-Galerkin perturbations $P_{i j}$ that are only applied to the convective terms are defined as:

$$
P_{i j}=k_{j}\left(U \frac{\partial N_{i}}{\partial X}+V \frac{\partial N_{i}}{\partial Y}\right) ; k_{j}=\frac{\alpha_{j} \bar{h}}{|V|} ; \alpha_{j}=\operatorname{coth} \frac{\gamma_{j}}{2}-\frac{2}{\gamma_{j}} ; \quad \gamma_{j}=\frac{|V| \bar{h}}{\varepsilon_{j}} ; j=1,2
$$

where $\gamma$ is the element Péclet number, $|V|$ is the absolute value of the velocity vector that represents the fluid average velocity within the element, $\bar{h}$ is the element average size, $\varepsilon_{1}=1 / \operatorname{Re}, \varepsilon_{2}=1 / \mathrm{Pe}$, and $\lambda$ is the Penalty parameter equal to $10^{9}$. Figure 2 shows the general bilinear quadrilateral element with $|V|$ and $\bar{h}$.

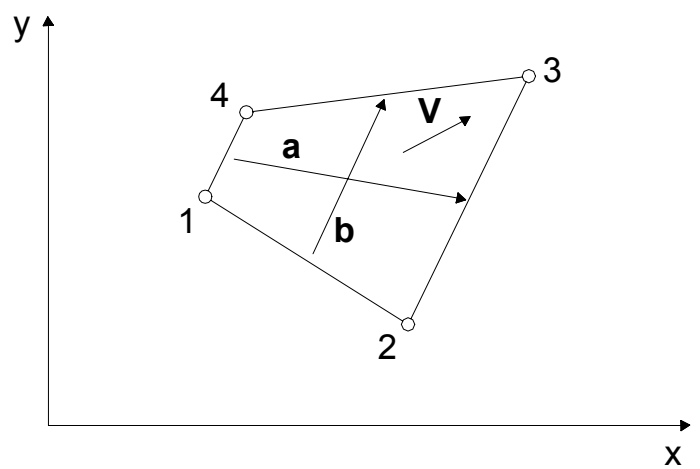

Figure 2: General bilinear quadrilateral element with vectors $\mathbf{a}$ and $\mathbf{b}$ and element velocity $\mathbf{V}$.

The element average size $\bar{h}$ in the flow direction is given by :

$$
\bar{h}=\frac{1}{|V|}\left(\left|h_{1}\right|+\left|h_{2}\right|\right)
$$

where $h_{1}, h_{2}, \boldsymbol{a}$, and $\boldsymbol{b}$ are defined as:

$$
\begin{gathered}
h_{1}=\boldsymbol{a} \cdot \boldsymbol{V} \\
h_{2}=\boldsymbol{b} \cdot \boldsymbol{V} \\
a_{1}=\frac{1}{2}\left(x_{2}+x_{3}-x_{1}-x_{4}\right) \\
a_{2}=\frac{1}{2}\left(y_{2}+y_{3}-y_{1}-y_{4}\right)
\end{gathered}
$$




$$
\begin{aligned}
& b_{1}=\frac{1}{2}\left(x_{3}+x_{4}-x_{1}-x_{2}\right) \\
& b_{2}=\frac{1}{2}\left(y_{3}+y_{4}-y_{1}-y_{2}\right)
\end{aligned}
$$

Vectors $\boldsymbol{a}$ and $\boldsymbol{b}$ are the vectors that are limited by the middle points of opposite sides and $h_{1}$ and $h_{2}$ are the projections of these vectors in the flow direction.

The most important characteristic of the Petrov-Galerkin method is that it does not add any transversal diffusion to the flow, that is, an orthogonal diffusion to the flow direction. $\alpha_{j}$ is the so-called artificial diffusion or the equilibrium diffusion added to the convective terms. In fact, it is the optimum diffusion found between the diffusions provided by the traditional Galerkin method and the Upwind one, which respectively are under-diffused and overdiffused methods. This helps one solve some numerical oscillations which arise from the 'battle' between elliptic and hyperbolic problems.

According to Bercovier and Engelman ${ }^{5}$ and Carey and Krishnan ${ }^{6}, \lambda$ is a problemindependent value, given that the governing parameters do not change drastically. This parameter must have a high value in order to have a 'quasi-incompressible' problem. Indeed, the Penalty theory comes from the Stokes viscosity law. Recalling the pressure formula:

$$
p=p_{s}-\left(\bar{\mu}+\frac{2}{3} \mu\right) \nabla . V
$$

where $p_{s}$ is the static or thermodynamic component of pressure, $p$ is the average pressure, $\bar{\mu}$ is the second viscosity coefficient, and $\mu$ is the first viscosity.

Stokes hypothesized that $p=p_{s}$, hence, $\bar{\mu}=-\frac{2}{3} \mu$. It was shown to be true for some gases; however experiments revealed that with liquids, $\lambda=\left(\bar{\mu}+\frac{2}{3} \mu\right)$ is a positive quantity that is much larger than $\mu$. $\lambda$ represents the fluid bulk viscosity. If the fluid is perfectly incompressible, $\lambda$ tends to be infinite. The basic idea of the Penalty formulation is to express the pressure by

$$
P=p-p_{s}=-\lambda \nabla \cdot \mathbf{V}
$$

where $\lambda$ is a very large number, and $P$ is a modified pressure, which can be seen in Eqs. (3) and (4). For linear interpolation of velocities, the pressure inside the element can be expressed by:

$$
P^{e}=-\frac{\lambda}{A^{e}} \int_{e}^{R}\left(\frac{\partial U}{\partial X}+\frac{\partial V}{\partial Y}\right) d e
$$


where $e$ denotes the element restriction and $A^{e}$ the element area.

Let one neglect some terms in the momentum equations and attain to those in the stiffness matrix, just to facilitate understanding of the Penalty parameter study. Substituting Eq. (16) in (3) and (4) with some manipulation and neglection of some terms which are now not important, the final linear system of equations would present this expression.

$$
\left[\mu \boldsymbol{K}_{1}+\lambda \boldsymbol{K}_{2}\right] \boldsymbol{d}=\boldsymbol{F}
$$

where $\boldsymbol{F}$ is the force matrix generated by the boundary conditions, $\boldsymbol{d}$ is the velocity vector only. Now, let one suppose that $\boldsymbol{K}_{2}$ is not singular and $\lambda$ is increased more and more in an attempt to reach incompressibility. Because $\mu$ and $\boldsymbol{K}_{1}$ are constant as $\lambda$ is increased, they can be neglected and the solution to Eq. (17) would be:

$$
\boldsymbol{d}=\frac{1}{\lambda} \boldsymbol{K}_{2}^{-1} \boldsymbol{F}
$$

Being that $\boldsymbol{K}_{2}$ and $\boldsymbol{F}$ are also constant, it can be noted that $\boldsymbol{d} \rightarrow 0$ as $\lambda \rightarrow \infty$. This is called 'locking' and is strictly related to the incompatibility between the pressure and velocity spaces. Hence, the only solution to this space is the velocity vector $\boldsymbol{V}=0$. It must be guaranteed that the Penalty matrix $\boldsymbol{K}_{2}$ be singular. This is accomplished by using the selective reduced integration of the Penalty term and the least square quadrature with a degree of precision lower than the necessary to guarantee an optimum convergence rate of matrix $\boldsymbol{K}_{1}$. Therefore, Fig. 3 shows a pair of elements used in this work in order to avoid locking.
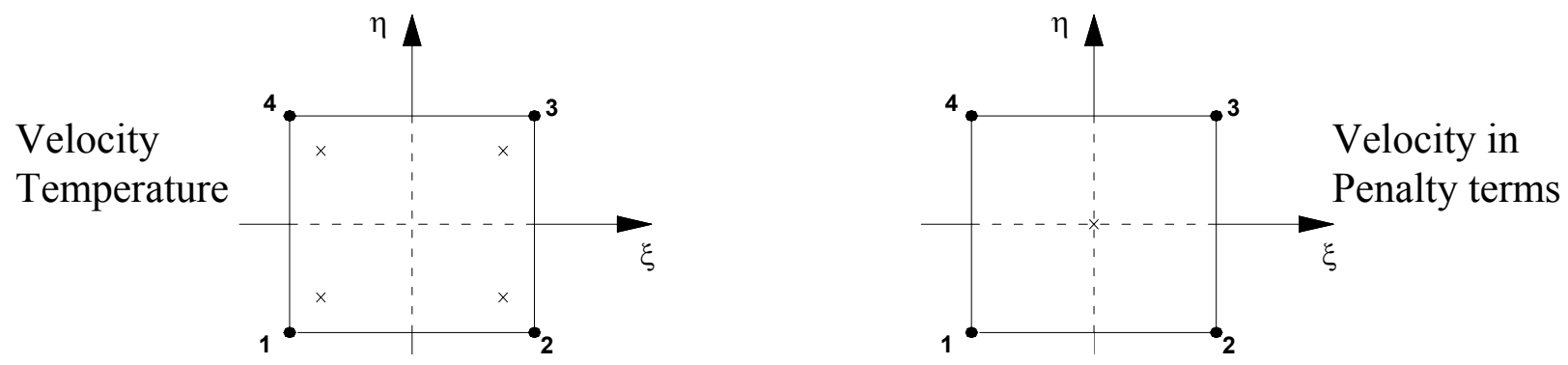

Figure 3: Real (a) and parent (b) elements for full and reduced integration, respectively.

The time integration is accomplished by the Euler backward semi-implicit method. Moreover, the convective and viscous terms are, respectively, calculated explicitly and implicitly.

Finally, the average Nusselt number along a surface $\mathrm{S}$ of a source can be written as follows: 


$$
N u=\frac{1}{S} \int_{S}\left[\frac{1}{\theta}\right] d s
$$

The algorithm is extensively validated by comparing the results of the present work with both the ones obtained in experimental and numerical investigations. Figures 4, 5, and 7 show the geometries and boundary conditions used in the first, second, and third comparisons, respectively.

The first comparison is accomplished not only by using the experimental results presented by Lee and Mateescu ${ }^{7}$ and Armaly ${ }^{8}$ et al., but also by the numerical ones achieved by Lee and Mateescu ${ }^{7}$, Gartling $^{9}$, Kim and Moin ${ }^{10}$, and Sohn ${ }^{11}$. The air flow of the present comparison analysis is taken as two-dimensional, laminar, incompressible, and under the unsteady regime. The domain is a horizontal upstream backward-facing step channel whose inlet has a fully developed velocity profile given by $u=24 y(0.5-y) \overline{\mathrm{U}}$ and $v=0$ in which $\mathrm{Re}=800$. The computational domain is shown in Fig. 4 where all walls are under the no-slip condition.

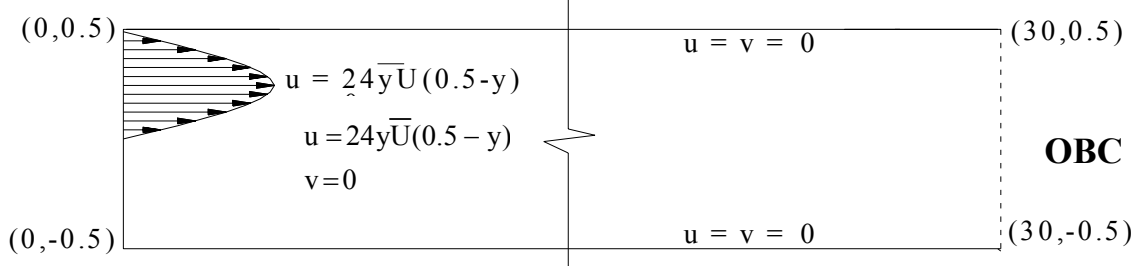

Figure 4: Geometry and boundary conditions for the first comparison.

Table 1 shows the results for the first comparison among the flow separation distances Xs and the flow reattachment distances Xrs on the upper surface. As for the bottom surface, the reattachment distances $\mathrm{Xr}$ are compared. $\mathrm{Hd}$ and $\mathrm{Hu}$ are the channel downstream and upstream heights, respectively. As it can be noticed, the results of the present work agree well with the ones from the literature.

Table1: Comparison of computed predictions and experimental measurements of dimensionless lengths (with respect to the channel height) of separation and reattachment on upper and lower walls.

\begin{tabular}{|c|c|c|c|c|c|c|c|c|}
\hline & \multirow[b]{2}{*}{$\begin{array}{r}\text { Length } \\
\text { on }\end{array}$} & \multicolumn{2}{|c|}{ Experimental results } & \multirow[b]{2}{*}{$\begin{array}{c}\text { Present } \\
\text { prediction }\end{array}$} & \multicolumn{4}{|c|}{ Computed results } \\
\hline & & $\begin{array}{c}\text { Lee and } \\
\text { Mateescu }^{7}\end{array}$ & $\begin{array}{c}\text { Armaly }^{8} \\
\text { et al. }\end{array}$ & & $\begin{array}{l}\text { Gartling's }{ }^{9} \\
\text { prediction }\end{array}$ & $\begin{array}{l}\text { Kim \& } \\
\text { Moin }^{10}\end{array}$ & $\begin{array}{c}\text { Lee and } \\
\text { Mateescu }^{7}\end{array}$ & Sohn $^{11}$ \\
\hline $\begin{array}{l}\text { Lower } \\
\text { Wall }\end{array}$ & $\mathrm{x}_{\mathrm{r}}$ & 6.45 & 7.0 & 5.75 & 6.1 & 6.0 & 6.0 & 5.8 \\
\hline Upper Wall & $\mathrm{x}_{\mathrm{s}}$ & 5.15 & 5.7 & 4.95 & 4.85 & - & 4.8 & - \\
\hline & $\mathrm{X}_{\mathrm{rs}}$ & 10.25 & 10.0 & 9.9 & 10.48 & - & 10.3 & - \\
\hline & $\mathrm{X}_{\mathrm{rs}}-\mathrm{X}_{\mathrm{s}}$ & 5.1 & 4.3 & 4.95 & 5.63 & 5.75 & 5.5 & 4.63 \\
\hline Reynolds & & 805 & 800 & 800 & 800 & 800 & 800 & 800 \\
\hline $\mathrm{Hd} / \mathrm{Hu}$ & & 2 & 1.94 & 2 & 2 & 2 & 2 & 2 \\
\hline
\end{tabular}


Figure 5 depicts the geometry and boundary conditions of the second comparison, which is performed with the numerical results shown by Comini ${ }^{12}$ et al. The contrasting study is carried out by considering a problem involving mixed convective heat transfer with the flow being two-dimensional, laminar, and incompressible in the unsteady regime.

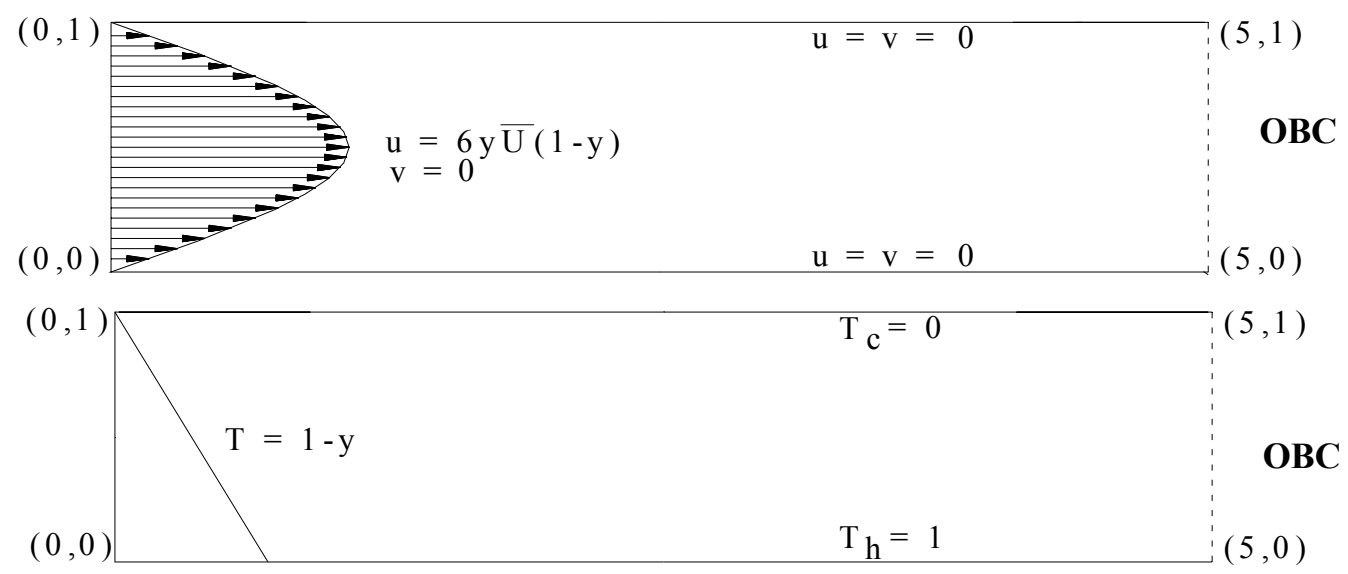

Figure 5: Geometry and boundary conditions for the second comparison.

Some values are chosen such as $\operatorname{Re}=10, \operatorname{Pr}=0.67$, and $\mathrm{Fr}=1 / 150$. The grid has 4000 quadrilateral four-node elements with $\Delta \mathrm{x}=0.1, \Delta \mathrm{y}=0.15, \Delta \mathrm{t}=0.01$ and 1000 iterations. Figure 6 displays the average Nusselt number on the upper surface versus time. After approximately iteration 500, the regime turns to be periodic with the average Nusselt number on the upper wall oscillating around a mean value of 2.44 . This value agrees satisfactorily with the one found by Comini ${ }^{12}$ et al. which is 2.34 , featuring a deviation of about $4 \%$.

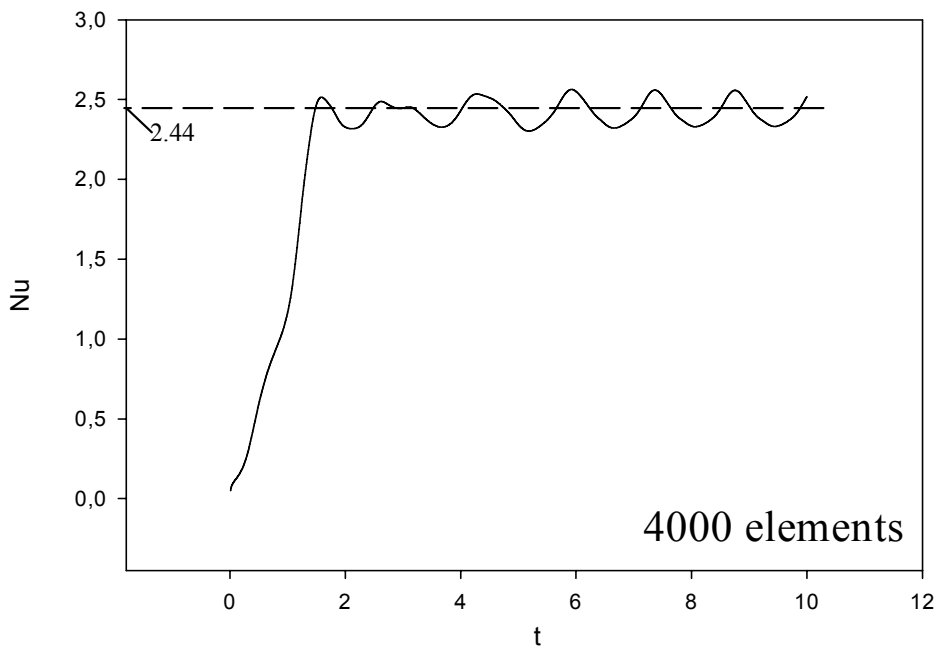

Figure 6: Average Nusselt number $\mathrm{Nu}$ measured along the upper surface versus time for a Poiseuille flow heated from below. 
Concluding the comparison, Fig. 7 pictures the third case studied to validate the mathematical modeling code. The mixed convection of air between two horizontal concentric cylinders with a cooled rotating outer cylinder is analyzed for $\operatorname{Pr}=0.7, \operatorname{Re}=10,50,100,150$, 200, 250,300,350, and 500, and $\mathrm{Ra}=10^{4}, 2 \times 10^{4}$, and $5 \times 10^{4}$. The domain is spatially discretized with 5976 non-structured four-node quadrilateral elements.
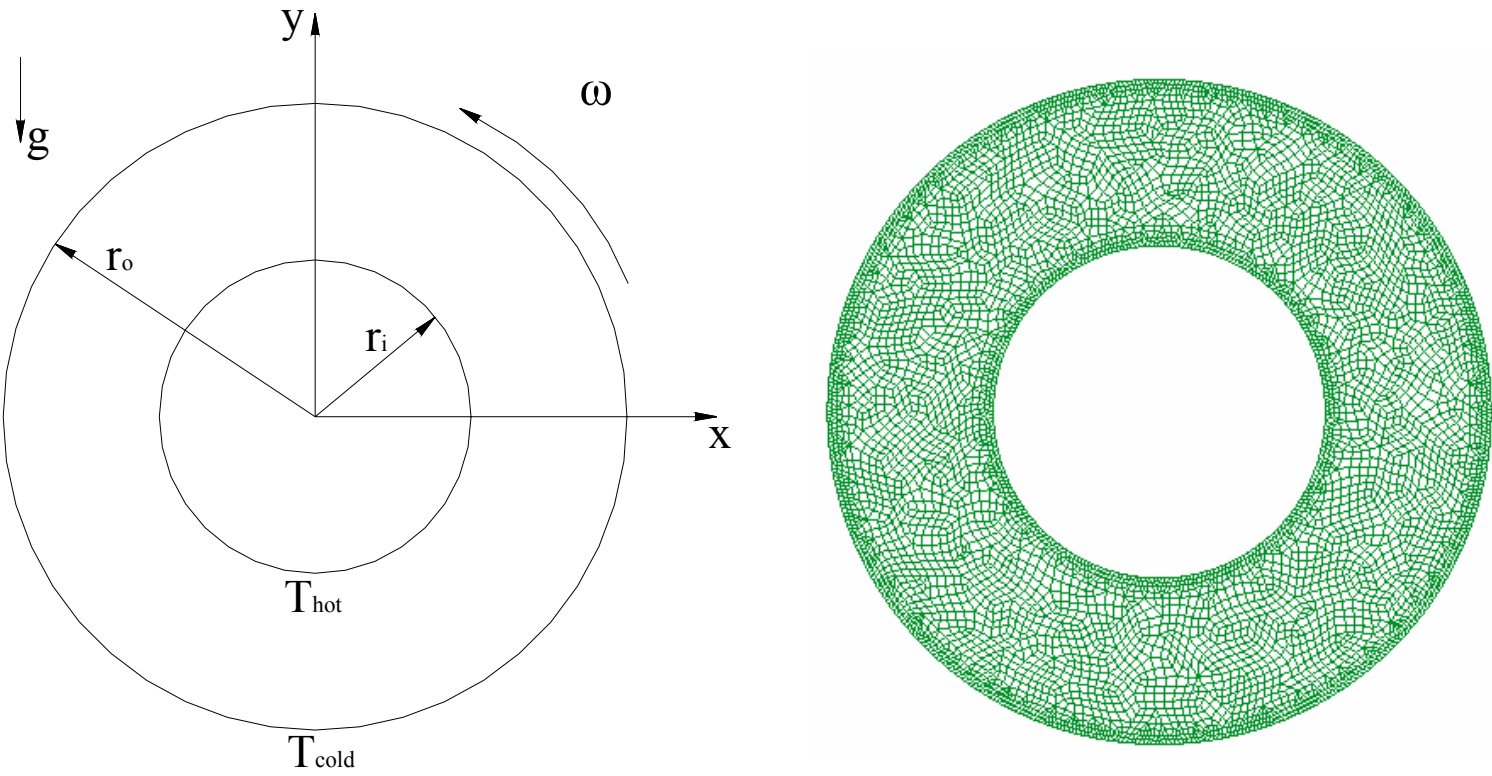

Figure 7: Comparison case: a) Geometry and boundary conditions b) mesh with 5976 elements.

Table 2 shows the average Nusselt numbers from the present work on the inner and outer cylinder surfaces, $\mathrm{NU}_{\text {CYLIN }}$ and $\mathrm{NU}_{\text {CYLOUT, }}$, respectively. It also shows the overall average Nusselt number $\left(\mathrm{NU}=\mathrm{NU}_{\mathrm{CYLIN}}+\mathrm{NU}_{\mathrm{CYLOUT}} / 2\right)$. These values are compared to the ones found in Yoo $^{1}$. They use a grid (radial $\mathrm{x}$ angular) of $(65 \mathrm{x} 64)$ points and a finite difference scheme. The results from the present work against to the ones in Yoo ${ }^{13}$ can be seen in Fig. 8. In fact, the results found in the present work are higher than the ones in Yoo $^{13}$, but still with a good agreement. This difference is likely due to different methods and different meshes. The time step used is 0.01 for almost all cases which are run in the present work and the number of iterations ranging from $10^{4}$ to $3 \times 10^{4}$.

\section{RESULTS}

The results presented here are obtained using the finite element method (FEM) and a structured mesh with rectangular isoparametric four-node elements in which $\Delta \mathrm{X}=0.1$ and $\Delta Y=0.05$. After studying the mesh sensibility for grids with $4000,5000,6000$, and 7000 elements, the one with 6000 elements is chosen taking into account the computational cost as well as a maximum deviation of $7 \%$ from the results obtained with the mesh with 7000 elements. The maximum computational cost is up to 6 hours or so. 
P. Guimaraes, G. Menon

Table 2: Values of Nusselt number for concentric cylinders with a mesh of 5976 elements.

\begin{tabular}{|c|c|c|c|c|c|c|}
\hline Rayleigh & Reynolds & Froud & Peclet & NU UYLIN $_{\text {CYLOUT }}$ & NU $_{\text {CYLOUT }}$ & NU \\
\hline 10000 & 50 & 0,175 & 35 & 2,6000 & 1,3221 & 1,9611 \\
\hline 10000 & 100 & 0,7 & 70 & 2,5622 & 1,3029 & 1,9326 \\
\hline 10000 & 150 & 1,575 & 105 & 2,4538 & 1,2506 & 1,8522 \\
\hline 10000 & 200 & 2,8 & 140 & 2,2697 & 1,1598 & 1,7147 \\
\hline 10000 & 250 & 4,375 & 175 & 2,0386 & 1,0426 & 1,5406 \\
\hline 10000 & 300 & 6,3 & 210 & 1,6269 & 0,8364 & 1,2317 \\
\hline 10000 & 350 & 8,575 & 245 & 1,4824 & 0,7629 & 1,1227 \\
\hline 10000 & 500 & 17,5 & 350 & 1,4374 & 0,7409 & 1,0892 \\
\hline 20000 & 100 & 0,35 & 70 & 3,1361 & 1,5964 & 2,3662 \\
\hline 20000 & 150 & 0,7875 & 105 & 3,0715 & 1,5645 & 2,3180 \\
\hline 20000 & 200 & 1,4 & 140 & 2,9515 & 1,5051 & 2,2283 \\
\hline 20000 & 250 & 2,1875 & 175 & 2,7821 & 1,4204 & 2,1013 \\
\hline 20000 & 300 & 3,15 & 210 & 2,5824 & 1,3206 & 1,9515 \\
\hline 20000 & 350 & 4,2875 & 245 & 2,3793 & 1,2168 & 1,7980 \\
\hline 20000 & 500 & 8,75 & 350 & 1,7730 & 0,9109 & 1,3420 \\
\hline 50000 & 100 & 0,14 & 70 & 3,9867 & 2,0324 & 3,0095 \\
\hline 50000 & 150 & 0,315 & 105 & 3,9587 & 2,0193 & 2,9890 \\
\hline 50000 & 200 & 0,56 & 140 & 3,8806 & 1,9798 & 2,9302 \\
\hline 50000 & 250 & 0,875 & 175 & 3,7695 & 1,9234 & 2,8465 \\
\hline 50000 & 300 & 1,26 & 210 & 3,6443 & 1,8616 & 2,7530 \\
\hline 50000 & 350 & 1,715 & 245 & 3,5035 & 1,7931 & 2,6483 \\
\hline 50000 & 500 & 3,5 & 350 & 3,0044 & 1,5373 & 2,2708 \\
\hline
\end{tabular}

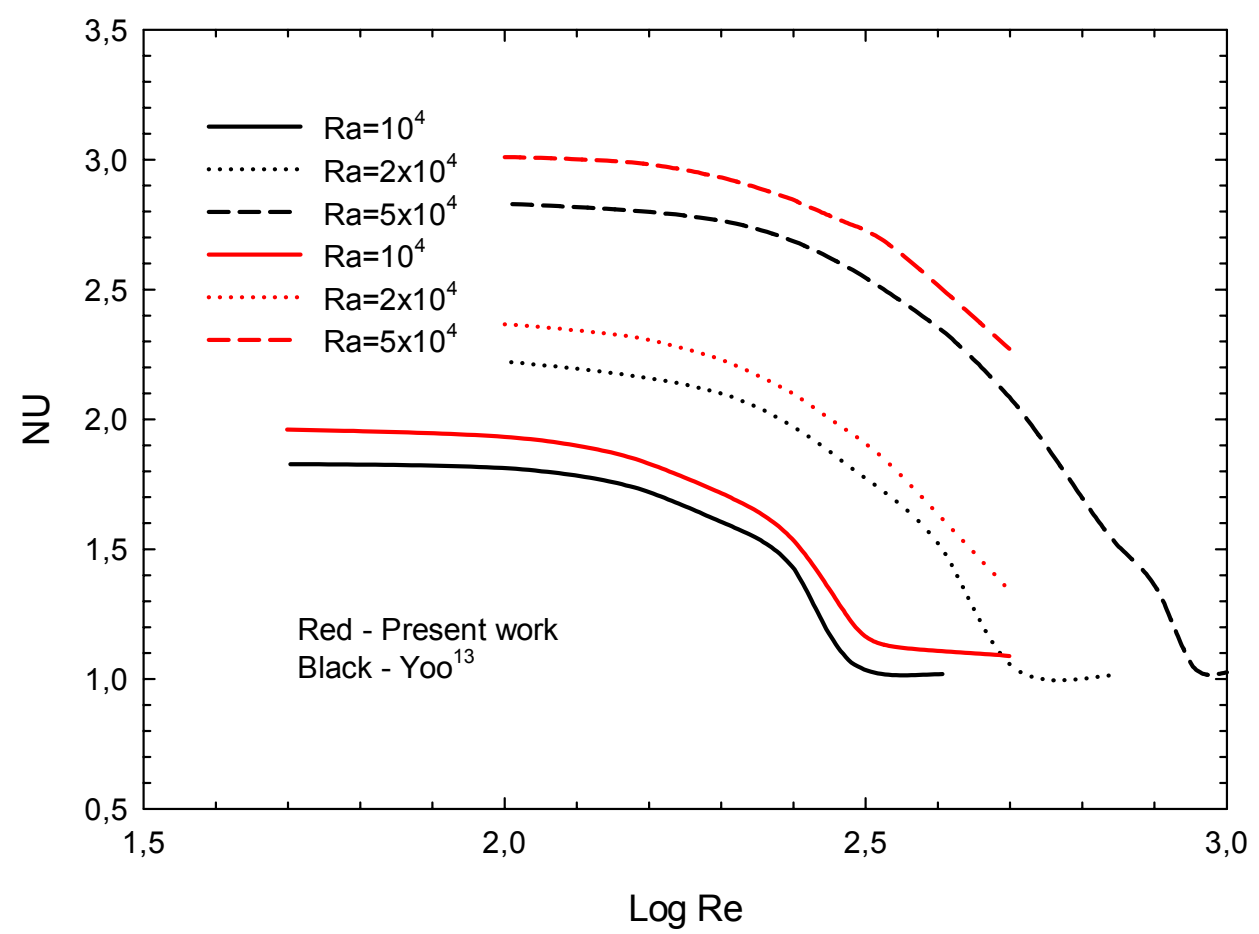

Figure 8: Comparison of overall average Nusselt number in a concentric cylinders problem. 
The temperature distributions for Reynolds numbers $\mathrm{Re}=1,10,50$, and 100, Grashof number $\mathrm{Gr}=10^{5}$, and inclination angles $\gamma=0^{\circ}$ (horizontal), $45^{\circ}$, and $90^{\circ}$ (vertical) are available in Fig. 9. For $\operatorname{Re}=1$ and $\gamma=0^{\circ}$ and $45^{\circ}$, there is a formation of thermal cells which are localized in regions close to the modules. When $\mathrm{Re}=1$, the flow is predominantly due to natural convection. As Re is increased, these cells are stretched and hence forced convection is characterized. By keeping Re constant, the inclination angle variation plays an important role in the temperature distribution. The effect of $\gamma$ on temperature is stronger when low velocities are present. For example, when $\operatorname{Re}=10$ and $\gamma=0^{\circ}, 45^{\circ}$ and $90^{\circ}$, this behavior is noted, that is, for $\gamma=0^{\circ}$ and $\operatorname{Re}=10$, a thermal cell is almost present, however, for $\gamma=45^{\circ}$ and $\operatorname{Re}=10$, those cells vanish. This is more evident when $\operatorname{Re}=1$ and $\gamma=45^{\circ}$ and $90^{\circ}$. It is worth observing that in some cases, the fluid heated in the first heater reaches the second one, and then the third one. Thus, this process of increasing temperature provides undesirable situations when cooling is aimed.

Figure 10 depicts the velocity vectors for $\operatorname{Re}=10$ and 100 and $\mathrm{Gr}=10^{5}$ for $\gamma=0^{\circ}, 45^{\circ}$, and $90^{\circ}$. It can be noted that for $\operatorname{Re}=10$ and $\gamma=0^{\circ}, 45^{\circ}$, and $90^{\circ}$, recirculations are generated by the fluid heated on the sources. For $\operatorname{Re}=10$ and $\gamma=0^{\circ}$, three independent recirculations appear. The distance among the heat sources enables the reorganization of the velocity profile until the fluid reaches the next source and then the recirculation process starts all over again. Now, concerning the cases where $\operatorname{Re}=10$ and $\gamma=45^{\circ}$ and $90^{\circ}$, there are two kinds of recirculations, that is, a primary recirculation along all channel that encompasses another two secondary recirculations localized just after the sources. Moreover, for these later cases, a fluid reversal is present at the outlet. As Re is increased by keeping $\gamma$ constant, these recirculations get weaker until they disappear for high Re. Clearly, one can note the effect of the inclination on the velocity vectors when $R e=10$. The strongest inclination influence takes place when it is between $0^{\circ}$ and $45^{\circ}$.

Figure 11 presents the average Nusselt number distributions on the heat sources, NUH1, NUH2, and NUH3 for Reynolds numbers $\mathrm{Re}=1,10,50,100$, and 1000, Grashof numbers $\mathrm{Gr}=10^{3}, 10^{4}$, and 105 , and inclination angles $\gamma=0^{\circ}, 45^{\circ}$, and $90^{\circ}$. In general, the average Nusselt number for each source increases as the Reynolds number is increased. By analyzing each graphic separately, it can be observed that NUH1 tends to become more distant from NUH2 and NUH3 as Reynolds number is increased, starting from an initial value for $\mathrm{Re}=1$ which is almost equal to NUH2 and NUH3. This agreement at the beginning means that a heater is not affecting one another. Here, it can be better perceived that behavior found in Fig. 9, where a heater is affected by an upstream one. That is the reason why NUH1 shows higher values. The only case in which the heaters show different values for $\mathrm{Re}=1$ is when $\mathrm{Gr}=10^{5}$ and $\gamma=90^{\circ}$. This difference is also noted in Fig. 9. Overall, the strongest effect on the average Nusselt number is between $0^{\circ}$ and $45^{\circ}$. Practically in all cases, NUH1, NUH2 , and NUH3 increase in this angle range, $0^{\circ}$ and $45^{\circ}$, while for $\mathrm{Gr}=10^{5}$ and $\mathrm{Re}=1000$, NUH2 and NUH3 decrease. When electronic circuits are concerned, the ideal case is the one which has the highest Nusselt number. Thus, angles $45^{\circ}$ and $90^{\circ}$ are the most suitable ones with not so much difference between them. An exception would be the case where $\mathrm{Gr}=10^{5}, \mathrm{Re}=1000$, and $\gamma=0^{\circ}$. 


\section{$\theta$}

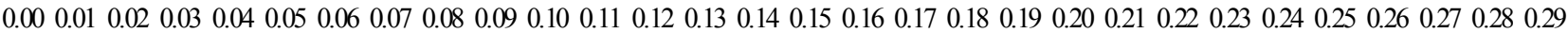

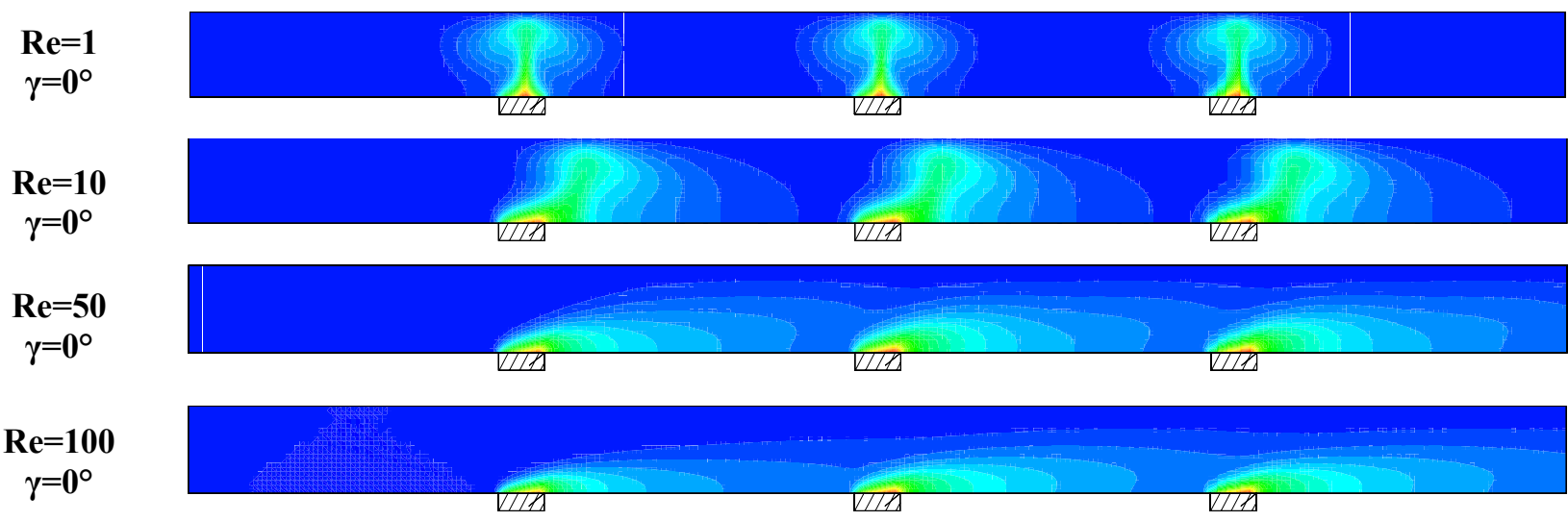

$\operatorname{Re}=1$ $\gamma=45^{\circ}$

$\mathbf{R e}=10$ $\gamma=45^{\circ}$

$\mathbf{R e}=\mathbf{5 0}$ $\gamma=45^{\circ}$

$\operatorname{Re}=100$ $\gamma=45^{\circ}$

$\operatorname{Re}=1$ $\gamma=90^{\circ}$

$\mathrm{Re}=10$ $\gamma=90^{\circ}$
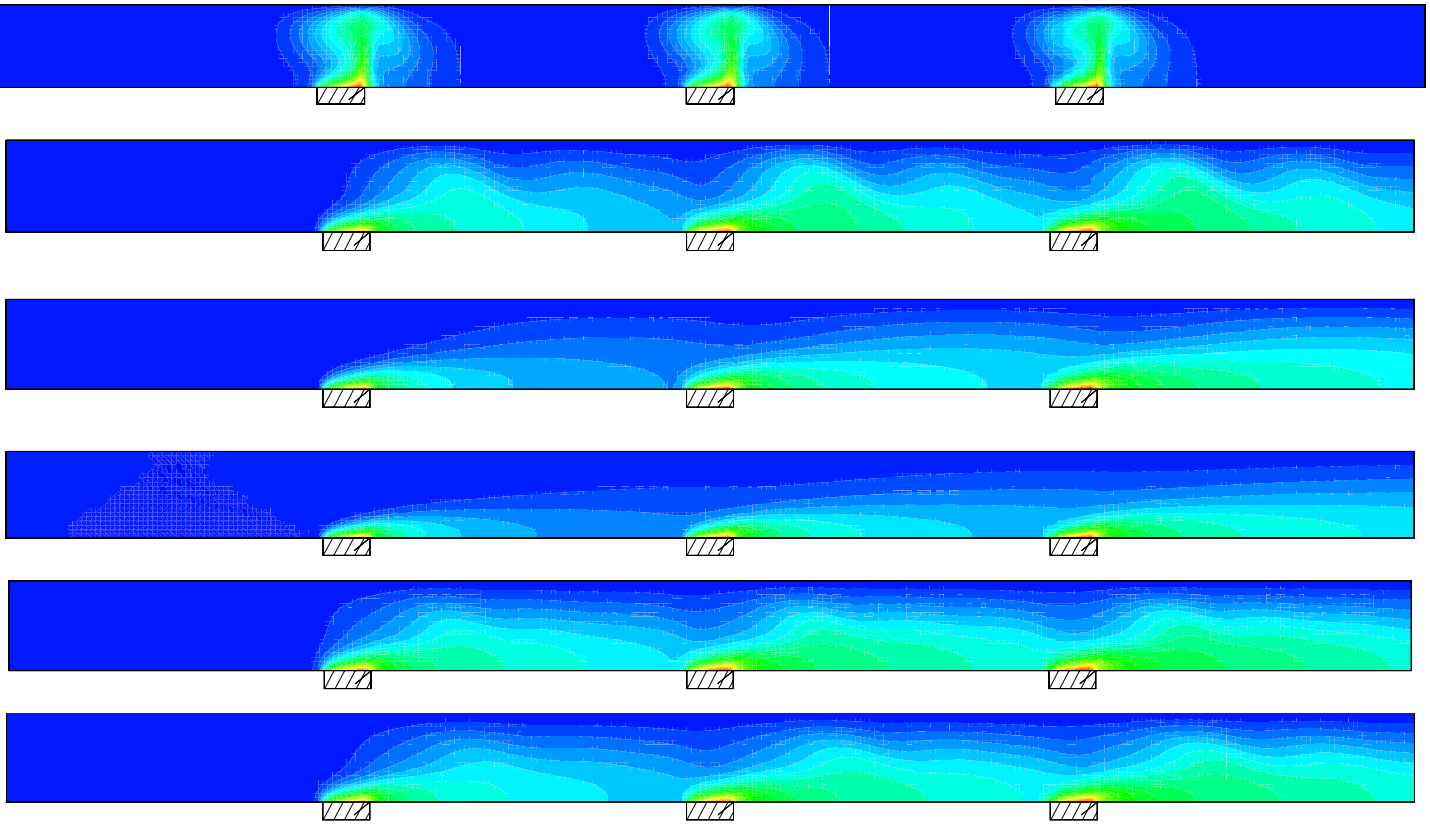

$\mathbf{R e}=\mathbf{5 0}$

$\gamma=90^{\circ}$

$\operatorname{Re}=100$

$\gamma=90^{\circ}$
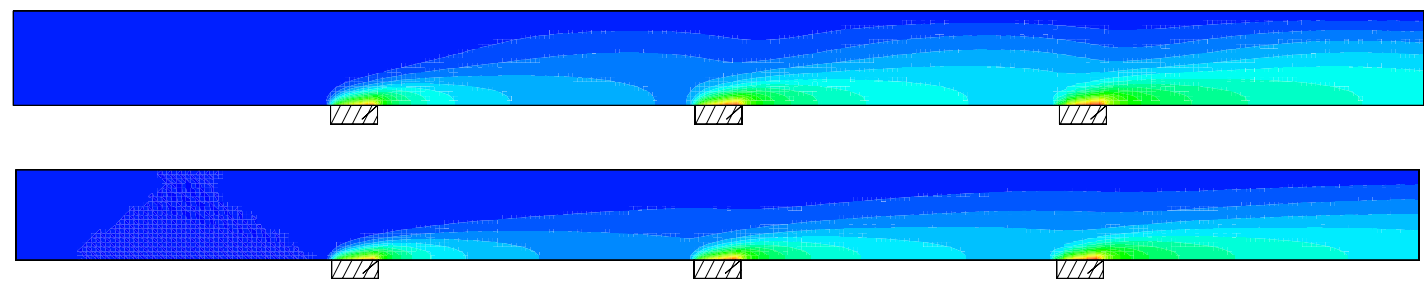

Figure 9: Isotherms for $\mathrm{Gr}=10^{5}, \operatorname{Re}=1,10,50,100$ and $\gamma=0^{\circ}, 45^{\circ}, 90^{\circ}$. 

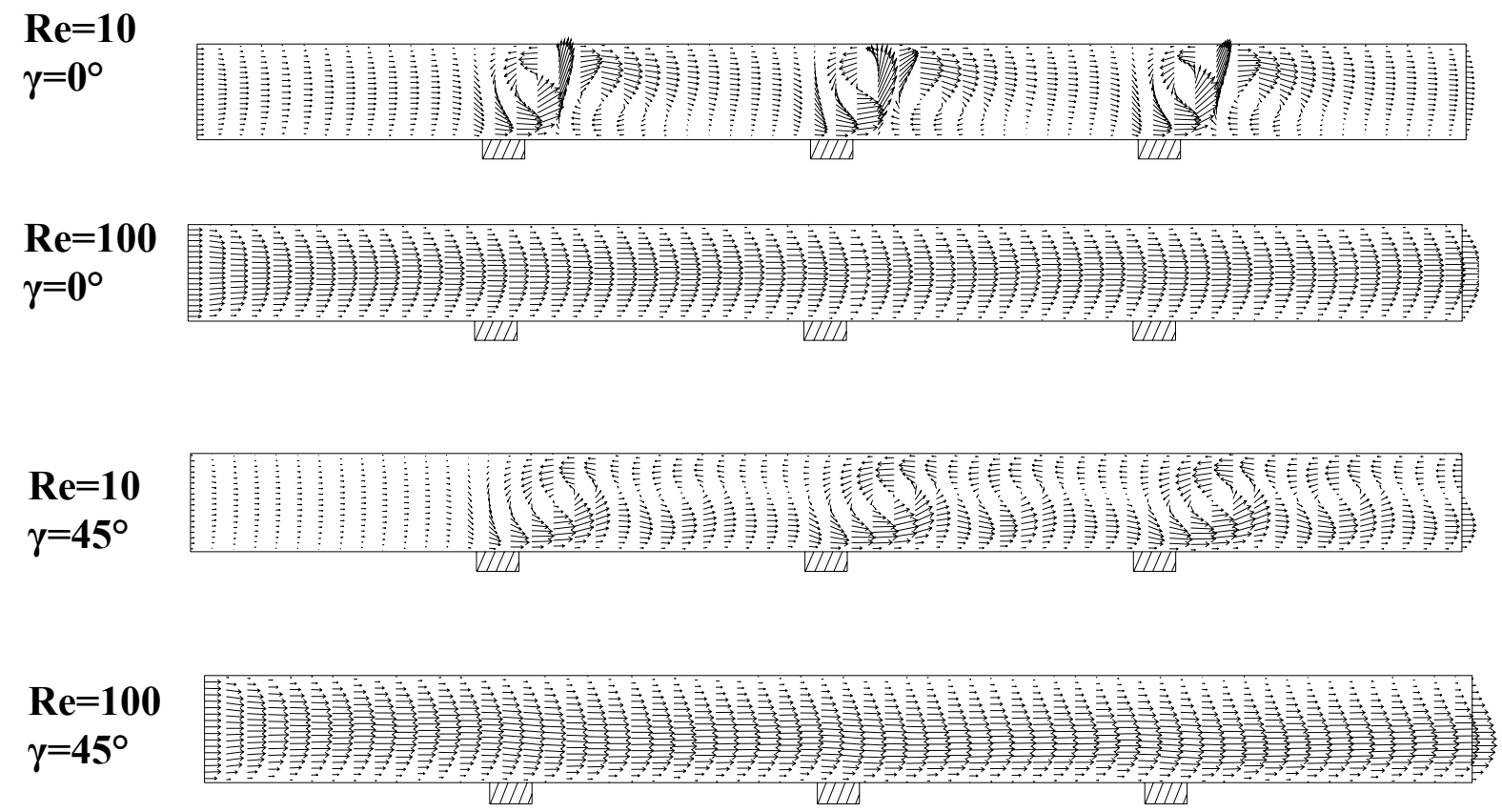

$$
\begin{aligned}
& \operatorname{Re}=10 \\
& \gamma=90^{\circ}
\end{aligned}
$$

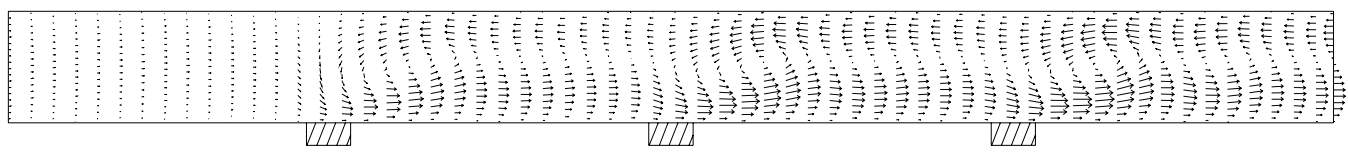

$$
\begin{aligned}
& \operatorname{Re}=100 \\
& \gamma=90^{\circ}
\end{aligned}
$$

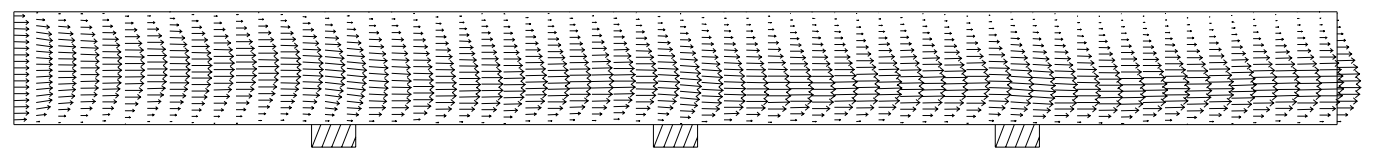

Figure 10: Velocity vectors for $\mathrm{Gr}=10^{5}, \operatorname{Re}=10$ and 100 , and $\gamma=0^{\circ}, 45^{\circ}$ and $90^{\circ}$.

Figure 12 presents the local dimensionless temperature distributions on the three heat sources for $\operatorname{Re}=10,100,1000, \mathrm{Gr}=10^{5}, \gamma=0^{\circ}, 45^{\circ}$, and $90^{\circ}$. Again, the cases where $\operatorname{Re}=10$ and 100 show the lowest temperatures when $\gamma=90^{\circ}$. On the other hand, this does not happen when $\operatorname{Re}=1000$, where the horizontal position shows the lowest temperatures along the modules. All cases in which $\gamma=0^{\circ}$, the second and third sources have equal temperatures. However, the first module shows lower temperatures. As mentioned before, this characterizes the fluid being heated by a previous source, thus, not contributing to the cooling of an upstream one.

Figure 13 presents the average Nusselt number variation on $\mathrm{H} 1, \mathrm{H} 2$, and $\mathrm{H} 3$ against the dimensionless time $\mathrm{t}$ considering $\mathrm{Re}=10,100, \mathrm{Gr}=10^{3}, 10^{4}, 10^{5}$ and $\gamma=90^{\circ}$. In the beginning, all three Nusselt numbers on $\mathrm{H} 1, \mathrm{H} 2$, and $\mathrm{H} 3$ have the same behavior and value. These numbers tend to converge to different values as time goes on. 
P. Guimaraes, G. Menon
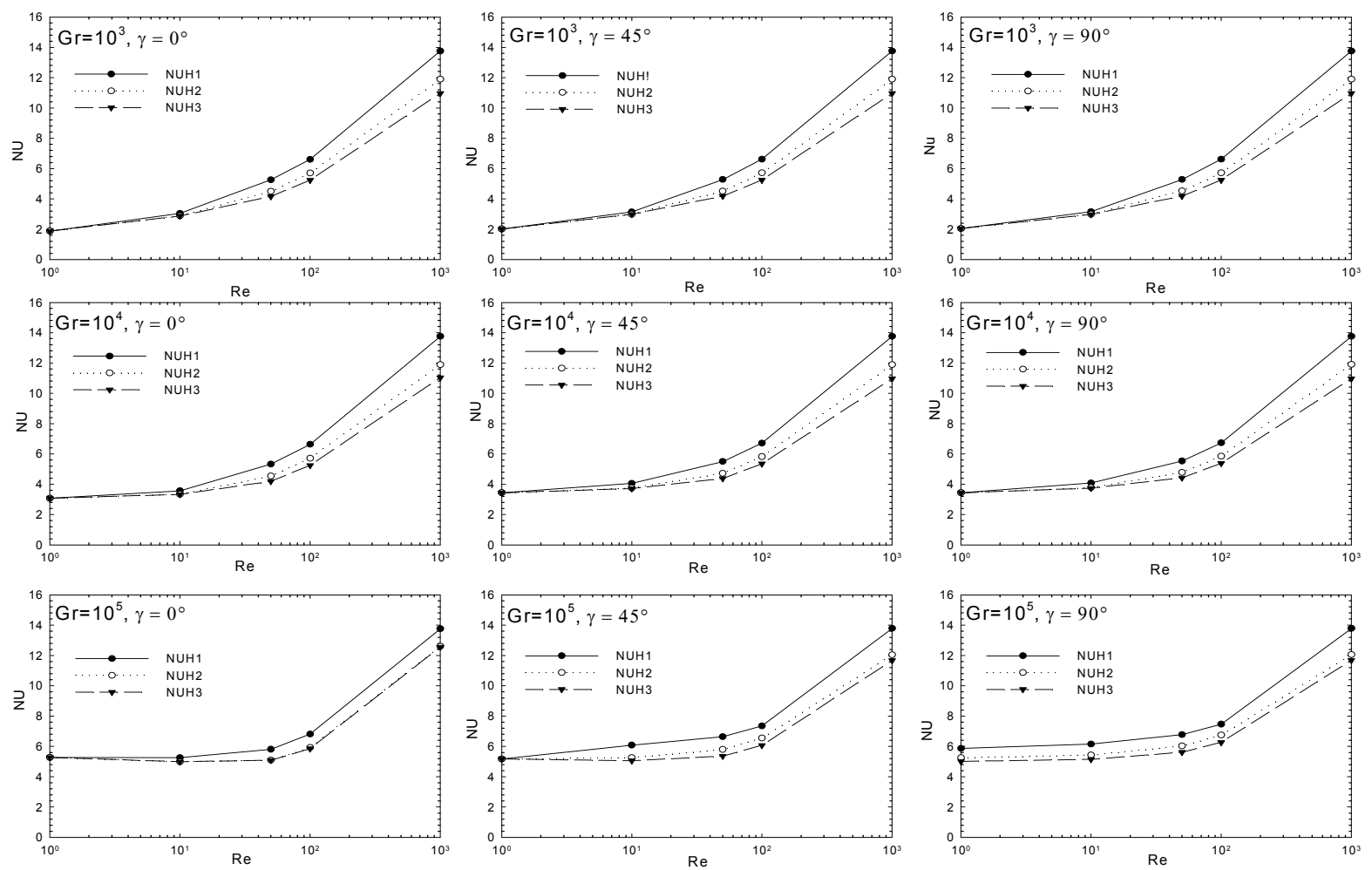

Figure 11: Average Nusselt number versus Reynolds number for $\mathrm{Gr}=10^{3}, 10^{4}, 10^{5}, \gamma=0^{\circ}, 45^{\circ}, 90^{\circ}$.
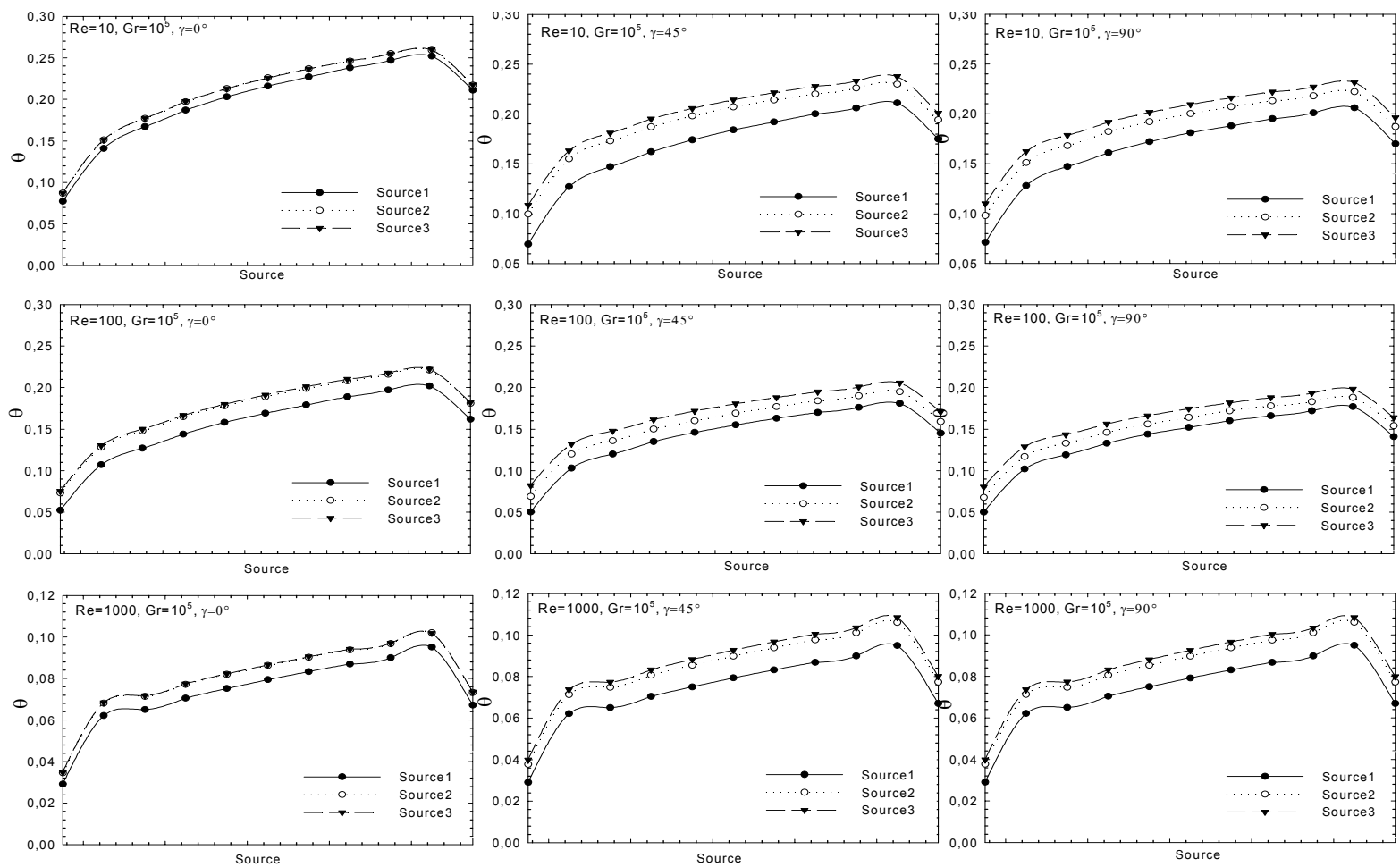

Figure 12: Module temperatures for $\operatorname{Re}=10,100,1000 ; \mathrm{Gr}=10^{5}, \gamma=0^{\circ}, 45^{\circ}, 90^{\circ}$. 
However, before they do so, they bifurcate at a certain point. This denotes the moment when a heated fluid wake from a previous source reaches a downstream one.
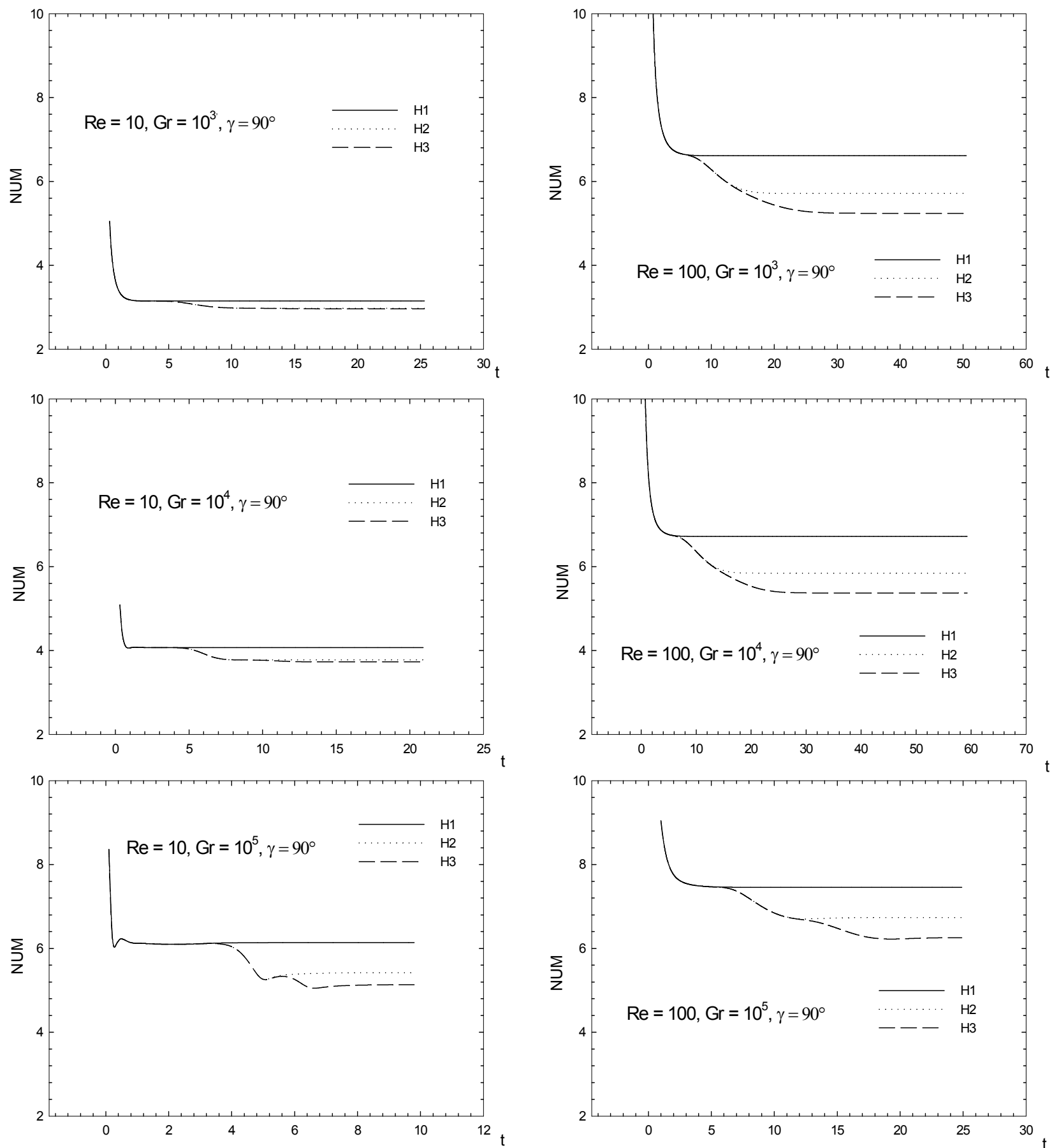

Figure 13: Module average Nusselt number in time for $\mathrm{Re}=10 \mathrm{e} 100, \mathrm{Gr}=10^{3}, 10^{4}, 10^{5}, \gamma=90^{\circ}$. 
P. Guimaraes, G. Menon

\section{CONCLUSION}

In this work, mixed convection heat transfer study in an inclined rectangular channel with three heat sources on the lower wall is carried out using the finite element method and the Petrov-Galerkin technique. Three comparisons with experimental and numerical results are performed. Good agreement is found. Effects on the temperature distribution and the Nusselt number along the heat sources as well as the velocity vectors in the domain are verified by varying the following parameters: inclination angle $\gamma\left(0^{\circ}, 45^{\circ}, 90^{\circ}\right)$, Reynolds number $\operatorname{Re}(1,10,50,100,1000)$, Grashof number $\operatorname{Gr}\left(10^{3}, 10^{4}, 10^{5}\right)$. In general, the inclination angle has a stronger influence on the flow and heat transfer as long as lower forced velocities are present, especially when the channel is between $0^{\circ}$ and $45^{\circ}$. It can be noted through the isotherms that in some cases some heat sources are reached by a hot wake coming from a previous module, thus, increasing their temperatures. Primary and secondary recirculations and reversal flow are present in some situations such as $\operatorname{Re}=10, \gamma=45^{\circ}$ and $90^{\circ}$. In problems where analysis of heat transfer on electronic circuits is aimed, cases with the lowest temperatures are the most suitable ones. Therefore, in agreement with the works by Guimarães and Menon ${ }^{1}$ and Choi and Ortega ${ }^{4}$, channel inclination angles $45^{\circ}$ and $90^{\circ}$, are the best ones with little difference between them. An exception is the case with $\mathrm{Gr}=10^{5}$ and $\operatorname{Re}=1000$, where $\gamma=0^{\circ}$ is the ideal channel inclination.

\section{ACKNOWLEDGEMENTS}

The authors thank CAPES for the financial support, without which this research would be impossible.

\section{REFERENCES}

[1] P.M. Guimarães and G.D. Menon, "Mixed Convection in an Inclined Channel with a Discrete Heat Source", Mecanica Computacional - Proceedings of the XII Congresso sobre Métodos Numéricos y sus Aplicaciones, 22, 1667-1681 (2003).

[2] J.H. Bae and J.M. Hyun, "Time-Dependent Buoyant Convection in an Enclosure with Discrete Heat Sources", Int. J. Thermal Sciences, In press(2003).

[3] P.N. Madhavan and V.M.K. Sastri, "Conjugate Natural Convection Cooling of Protruding Heat Sources Mounted on a Substrate Placed Inside an Enclosure: a Parametric Study", Comput. Methods Appl. Mech Engrg., 188, 187-202 (2000).

[4] C.Y. Choi and A. Ortega, "Mixed Convection in an Inclined Channel With a Discrete Heat Source", Int. J. Heat Mass Transfer, 36, 3119-3134 (1993).

[5] M. Bercovier and M. Engelman, "A Finite Element for the Numerical Solution of Viscous Incompressible Flow", J. Comput. Phys., 30, 181-201 (1979).

[6] G. F. Carey and Krishnam, "Penalty Approximation of Stokes Flow", Comput. Methods Appl. Mech. Eng., 35, 169-206 (1982).

[7] T. Lee and D. Mateescu, "Experimental and Numerical Investigation of 2-D BackwardFacing Step Flow", J. Fluids and Structures, 12, 703-716 (1988). 
[8] B. F. Armaly, F. Durst, and J.C.F. Pereira \& B. Schonung, "Experimental and Theoretical Investigation of Backward-Facing Step Flow", J. Fluid Mechanics, 127, 473-496 (1983).

[9] D.K. Gartling, "A Test Problem for Outflow Boundary Conditions - Flow over a Backward-Facing Step", Int. J. Num. Meth. in Fluids, 11, 953-967 (1990).

[10] J. Kim and P. Moin, "Application of a Fractional-Step Method to Incompressible Navier-Stokes Equations", J. Comp. Physics, 59, 308-323 (1985).

[11] J. Sohn, "Evaluation of FIDAP on Some Classical Laminar and Turbulent Benchmarks", Int. J. Num. Meth. in Fluids, 8, 1469-1490 (1988).

[12] G. Comini, M. Manzam and G. Cortella, "Open Boundary Conditions for the Streamfunction -Vorticity Formulation of Unsteady Laminar Convection", Num. Heat Transfer, Part B, 31, 217-234 (1997).

[13] J. Yoo, "Mixed Convection of Air Between Two Horizontal Concentric Cylinders with a Cooled Rotating Outer Cylinder", Int. J. Heat Mass Transfer, 41, No. 2, 293-302 (1998). 